\title{
Functional environmental proteomics: elucidating the role of a $c$-type cytochrome abundant during uranium bioremediation
}

\author{
Jiae Yun ${ }^{1}$, Nikhil S Malvankar ${ }^{1,2}$, Toshiyuki Ueki ${ }^{1}$ and Derek R Lovley ${ }^{1}$ \\ ${ }^{1}$ Department of Microbiology, University of Massachusetts, Amherst, MA, USA and ${ }^{2}$ Department of Physics, \\ University of Massachusetts, Amherst, MA, USA
}

\begin{abstract}
Studies with pure cultures of dissimilatory metal-reducing microorganisms have demonstrated that outer-surface $c$-type cytochromes are important electron transfer agents for the reduction of metals, but previous environmental proteomic studies have typically not recovered cytochrome sequences from subsurface environments in which metal reduction is important. Gel-separation, heme-staining and mass spectrometry of proteins in groundwater from in situ uranium bioremediation experiments identified a putative c-type cytochrome, designated Geobacter subsurface c-type cytochrome A (GscA), encoded within the genome of strain M18, a Geobacter isolate previously recovered from the site. Homologs of GscA were identified in the genomes of other Geobacter isolates in the phylogenetic cluster known as subsurface clade 1, which predominates in a diversity of $\mathrm{Fe}$ (III)reducing subsurface environments. Most of the gscA sequences recovered from groundwater genomic DNA clustered in a tight phylogenetic group closely related to strain M18. GscA was most abundant in groundwater samples in which Geobacter sp. predominated. Expression of gscA in a strain of Geobacter sulfurreducens that lacked the gene for the c-type cytochrome OmcS, thought to facilitate electron transfer from conductive pili to Fe(III) oxide, restored the capacity for $\mathrm{Fe}$ (III) oxide reduction. Atomic force microscopy provided evidence that GscA was associated with the pili. These results demonstrate that a $c$-type cytochrome with an apparent function similar to that of OmcS is abundant when Geobacter sp. are abundant in the subsurface, providing insight into the mechanisms for the growth of subsurface Geobacter sp. on Fe(III) oxide and suggesting an approach for functional analysis of other Geobacter proteins found in the subsurface.
\end{abstract}

The ISME Journal (2016) 10, 310-320; doi:10.1038/ismej.2015.113; published online 3 July 2015

\section{Introduction}

Geobacter sp. are abundant in various subsurface environments in which Fe(III) reduction is an important biogeochemical process and they can have an important role in the anaerobic bioremediation of groundwater contaminated with metal or organic contaminants (Lovley et al., 2011). The ability of Geobacter sp. to reduce soluble U(VI) to poorly soluble U(IV) (Lovley et al., 1991) has been exploited as an in situ bioremediation strategy to prevent the migration of uranium in contaminated subsurface environments (Lovley et al., 2011; Williams et al., 2013).

Geobacter sulfurreducens has served as the primary model species for elucidating the physiology of Geobacter sp. (Lovley et al., 2011; Mahadevan et al., 2011). Functional genomic analysis of G. sulfurreducens has led to molecular tools for diagnosing the

Correspondence: T Ueki, Department of Microbiology, University of Massachusetts Amherst, Morrill Science Center IV North, 639 North Pleasant Street, Amherst, MA 01003, USA.

E-mail: tueki@microbio.umass.edu

Received 7 January 2015; revised 27 May 2015; accepted 4 June 2015; published online 3 July 2015 physiological status of subsurface Geobacter sp. during in situ uranium bioremediation based on gene transcript and proteomic approaches (Lovley et al., 2011; Mahadevan et al., 2011). These approaches have been effective in evaluating rates of metabolism and growth, nutrient limitations and stress responses because the genes for these functions are highly conserved among Geobacter sp. and gene function could first be elucidated in the genetically tractable $G$. sulfurreducens (Lovley et al., 2011). In contrast, the lack of conservation of outer-surface $c$-type cytochromes within the Geobacteraceae (Butler et al., 2009, 2010) has made it difficult to develop similar molecular strategies to meaningfully interpret the transcriptomic or proteomic data related to the expression of outer-surface $c$-type cytochromes (Chin et al., 2004), which have an essential role in extracellular electron transfer (Lovley, 2011; Lovley et al., 2011).

For example, the multi-heme $c$-type cytochrome, OmcS (Qian et al., 2011), is essential for Fe(III) oxide reduction in G. sulfurreducens (Mehta et al., 2005). OmcS is localized on the pili of $G$. sulfurreducens (Leang et al., 2010) that are electrically conductive 
(Reguera et al., 2005; Malvankar et al., 2011, 2014; Malvankar and Lovley, 2014). Multiple lines of evidence have demonstrated that OmcS is not responsible for long-range electron transport along the pili, (Leang et al., 2010; Malvankar et al., 2011, 2012; Vargas et al., 2013; Liu et al., 2014). Therefore, the proposed role for OmcS is to facilitate electron transfer from the pili to Fe(III) oxide (Lovley, 2011, 2012).

Further evidence that a mediator for electron transfer from pili to $\mathrm{Fe}$ (III) oxide is needed was the finding that magnetite, a product of microbial Fe(III) oxide reduction (Lovley et al., 1987; Lovley, 1991), binds to the pili of $G$. sulfurreducens accelerating Fe(III) oxide reduction and restoring the capacity for $\mathrm{Fe}(\mathrm{III})$ oxide reduction in the OmcS-deficient mutant (Liu et al., 2015). These results demonstrate that other molecules, even non-biological minerals with the capacity for electron transfer, can substitute for OmcS to facilitate electron transfer from pili to Fe(III) oxides.

None of the Geobacter sp. in Subsurface Clade I, the phylogenetic group that typically predominates in subsurface environments in which Fe(III) is being actively reduced (Holmes et al., 2007), encode an OmcS homolog (Butler et al., 2009, 2010). The lack of methods for genetic manipulation of Geobacter sp. in Subsurface Clade 1 has hindered the efforts to determine whether there are one or more cytochromes that have a role similar to OmcS in the Geobacter sp. that are most abundant during in situ uranium bioremediation.

Geobacter sp. contain a large number of $c$-type cytochromes (Lovley et al., 2011), but previous proteomic studies of the microbial community during in situ uranium bioremediation sites, identified few, if any, $c$-type cytochromes (Wilkins et al., 2009, 2013; Callister et al., 2010). One reason for this may be the poor conservation of $c$-type cytochromes in Geobacter sp. (Lovley et al., 2011) and thus a lack of the relevant $c$-type cytochrome gene sequences in databases. Furthermore, it can be difficult to identify $c$-type heme-containing peptides with mass spectrometry, leading to an underrepresentation of heme-containing peptides even in studies of pure cultures (Romine et al., 2004; Yang et al., 2005; Merkley et al., 2012).

The study summarized here was designed to evaluate which cytochromes might be important in extracellular electron transfer during Geobacter-catalyzed in situ uranium bioremediation and the function of those cytochromes. This was accomplished with environmental proteomic analysis including a biochemical method for the detection of $c$-type heme-containing proteins and the study of cytochrome function via heterologous expression in G. sulfurreducens.

\section{Materials and methods}

Bacterial strains and growth conditions

G. bemidjiensis BEM (Nevin et al., 2005), G. sulfurreducens DL1 (Caccavo et al., 1994; Coppi et al., 2001) and its mutants were routinely grown anaerobically at $30^{\circ} \mathrm{C}$ in NBAF media (Coppi et al., 2001) unless indicated otherwise. Acetate (10 mM) was added when Fe(III) oxide (100 $\left.\mathrm{mmol} \mathrm{l}^{-1}\right)$ was the electron acceptor (Lovley and Phillips, 1987). Kanamycin $\left(200 \mu \mathrm{g} \mathrm{ml}^{-1}\right)$ and isopropyl $\beta$-D-1-thiogalactopyranoside (IPTG) $\left(1 \mathrm{mg} \mathrm{ml}^{-1}\right)$ were added when necessary.

\section{Sampling site description}

During the summer of 2007 and 2008, in situ uranium bioremediation experiments were conducted as part of the Rifle Integrated Field Research challenge, at the uranium-contaminated aquifer in Rifle, CO, USA. Acetate was added to the groundwater to stimulate the growth of dissimilatory metal-reducing microorganisms (Williams et al., 2011). This site, methods for introducing acetate into the subsurface, and groundwater sample collection methods have previously been described in detail (Mouser et al., 2009; Wilkins et al., 2009; Williams et al., 2011). Groundwater samples from wells D05 and D07 of the 2007 field experiment and wells D04 and D07 in the 2008 field experiment were investigated because previous studies suggested that Geobacter sp. were abundant at the time points studied (Mouser et al., 2009; Wilkins et al., 2009; Williams et al., 2011).

\section{Identification of c-type heme-containing proteins}

The proteins from filters that collected groundwater bacteria were extracted as previously described (Yun et al., 2011) with the modification that the ultrafiltration at the last step was replaced by adding $200 \mu \mathrm{l}$ of PPS (protein precipitation solution, MP Biomedicals, Santa Ana, CA, USA) to $1 \mathrm{ml}$ of protein extract. Protein concentration was determined by measuring absorbance at $280 \mathrm{~nm}$ prior to the protein precipitation step using dilutions of $G$. bemidjiensis cell extract of known protein concentration. Extracted groundwater protein (6 mg) was analyzed with SDS-PAGE (Bollag et al., 1996), and $C$-type heme-containing proteins were visualized by staining using $N, N, N$, N'-tetramethylbenzidine as described previously (Thomas et al., 1976; Francis and Becker, 1984). Major bands were selected and excised from the gel after hemestaining, subjected to reduction, alkylation and ingel digestion (trypsin or Asp-N), and analyzed with liquid chromatography-tandem mass spectrometry (LC/MS/MS) (LCQ Deca ESI Ion Trap, Thermo, Waltham, MA, USA), performed by the UMASS Proteomics and Mass Spectrometry facility (Pazour et al., 2005). The raw data were converted to MS/MS spectra peak lists with the LCQ_DTA program (Thermo). The analyzed results were compared against the NCBInr 032810 database with the Mascot algorithm (http://www.matrixscience.com). 
Antibody production and western blot analyses

Antibodies were produced against polypeptides that were designed to be specific to the Geobacter subsurface $c$-type cytochrome A (GscA) homologs found in Geobacter sp., or the RpoA of Geobacter subsurface clade 1, because the majority of Geobacteraceae $16 \mathrm{~S}$ ribosomal RNA sequences recovered from the uraniumcontaminated aquifer clustered in this phylogenetic clade (Holmes et al., 2007). The selected amino acid sequences of the polypeptides were HKIHMGNRLTC for the GscA-specific antibody, and NFPDPEIMRRLRGE for the RpoA-specific antibody. Peptide synthesis and production of the polyclonal antibodies in rabbits against these polypeptides were performed by New England Peptide, LLC (Gardner, MA, USA).

In order to generate purified proteins as standards for western blot analysis, gscA and $r p o A$ were amplified from the genome of $G$. bemidjiensis with the gSCA primers gscA_NdeF (5'-ACAAGGAGGACA TATGCAAGGCACG-3') and gscA_XhoR (5'-GGCGCT TATTGCTCGAGCTGGTGAACC-3') and the rpoA primers RpoAF_Nd (5'-GGGGATCCATATGTATAG AAACTG-3') and RpoAR_E1_His (5'- AGTCTTGAAT TCTAGTGGTGGTGGTGGTGGTGTTCTTCTTTCT GC TCGCCGC-3'). The amplified PCR products were digested with NdeI and XhoI for gscA, or NdeI and EcoRI for rpoA and ligated with pET24b (Novagen, Billerica, MA, USA) treated with the same enzymes. Escherichia coli BL21(DE3) (Studier et al., 1990) was used as the host. For expression of GscA, pEC86 was co-transformed to enable constitutive expression of the cytochrome $C$ maturation genes (Arslan et al., 1998). Purified His-tagged proteins were obtained using Ni-NTA agarose (Qiagen, Germantown, MD, USA) according to the manufacturer's protocol. Western blotting analyses were performed as previously described (Yun et al., 2011).

\section{Diversity analysis}

In order to evaluate the phylogenetic diversity of gscA during active Fe(III) reduction in the subsurface, DNA was extracted from filter-collected biomass from well D07 on day 15 of the 2007 field study with the FastDNA SPIN kit for soil (MP Biomedicals). Degenerate primers of gscA1840F (5'-TWCWC CGGMRGCCCSWSYTTCCTGMT-3') and gscA2554R (5'-CGGCRTGGAYRCCGTGRATCADRTCCTT-3') were designed to amplify the gscA homologs from the in situ uranium bioremediation site. The $16 \mathrm{~S}$ ribosomal RNA gene was amplified with primers 8F (Eden et al., 1991) and 519R (Lane et al., 1985) under the previously determined amplification condition (Anderson et al., 2003). The resultant PCR products purified from a $1 \%$ agarose gel were cloned into the TOPO TA vector pCR2.1 (Invitrogen, Waltham, MA, USA). Inserts of the clones were amplified with the M13F and M13R primers, and sequenced with the M13F primer.

DNA sequences of clone libraries were compared with the database in GenBank with BlastN, BlastX (Altschul et al., 1997), or programs in the Greengenes
Web site (http://greengenes.lbl.gov) (DeSantis et al., 2006a, b). The translated amino acid sequences of gscA clone libraries were aligned using Clustal W (Thompson et al., 1994). Neighbor-joining trees of amino acid sequences were constructed with the MEGA 4.0 (http://www.megasoftware.net) (Tamura et al., 2007) with default parameters. Bootstrap values were obtained from 1000 replicates. The sequences in this study were deposited in GenBank (GscA homologs: KP338821-KP338928, 16 S ribosomal RNA: KP338929-KP338993).

\section{Expression of GscA in omcS-deficient strain of}

G. sulfurreducens

In order to evaluate the function of GscA, an expression plasmid containing gscA was constructed. The gscA homolog, Gbem_3371 was amplified from the genome of $G$. bemidjiensis with the primers Gbem_3371_EcoRI (5'-CATCTGAATTCAGA CAAGGAGGATTT-3') and Gbem_3371_HindIIIR (5'-GCTCCCGTTATAAGCTTTTGGATTT-3'), and the amplified PCR product was ligated with pCD341 (Coppi et al., 2001) treated with same enzymes. The correctly cloned plasmid was transformed into the omcS-deficient strain of G. sulfurreducens (Mehta et al., 2005) by electroporation (Coppi et al., 2001). The expression of GscA in the omcS-deleted G. sulfurreducens mutant by induction with IPTG was confirmed by SDS-PAGE followed by Coomassie brilliant blue staining (data not shown). The ability of the G. sulfurreducens strains to reduce insoluble Fe(III) oxides was evaluated by the determination of $\mathrm{Fe}(\mathrm{II})$ concentration with the ferrozine assay (Lovley and Phillips, 1986).

\section{Atomic force microscopy}

G. sulfurreducens $\triangle$ omcS/pCD341 and G. sulfurreducens $\Delta$ omcS/pCD-gscA were grown in NBAF liquid medium supplemented with kanamycin and IPTG at $25^{\circ} \mathrm{C}$. Pili expression of cells was verified by negatively staining cells and examining with transmission electron microscopy. These pili-expressing cells were placed on freshly cleaved mica surface and atomic force microscopy was conducted to localize and map pili and any associated cytochrome-like globules aligned along the pili as described previously (Malvankar et al., 2012).

\section{Results and discussion}

Identification of c-type heme-containing proteins from the groundwater at the in situ uranium bioremediation site

Although $c$-type cytochromes are abundant in Geobacter sp. that bloom when acetate is added to groundwater at the Rifle, Colorado study site to promote in situ uranium bioremediation (Lovley et al., 2011), previous studies of the microbial community that employed a global proteomics 
approach, detected few, if any, $c$-type cytochromes (Wilkins et al., 2009, 2013; Callister et al., 2010). As an alternative heme-specific approach, proteins extracted from groundwater samples collected during two in situ bioremediation experiments were separated with SDS-PAGE and visualized with heme staining. Two major bands with a molecular weight of $>80 \mathrm{kD}$ and ca. $30 \mathrm{kD}$ were recovered in groundwater samples in which previous studies (Mouser et al., 2009; Wilkins et al., 2011; Williams et al., 2011; Yun et al., 2011) found an abundance of Geobacter sp. (Figure 1).

The abundant heme-staining bands from the day 15 sample from well D05 were excised from the hemestained gel for proteomic analysis. A number of peptides were detected, but no $c$-type heme-containing proteins could be identified with LC/MS/MS when the samples were digested with trypsin, or when the lower band was digested with Asp-N. One possibility for this is that many $c$-type cytochromes in Geobacter sp. are poorly conserved (Butler et al., 2009; Butler et al., 2010), and thus there is a high probability that an isolate containing the sequence for this cytochrome is yet to be isolated and sequenced.
However, analysis of the upper band digested with Asp-N identified two peptides (QDANILGAED, score 29 and GDGSYTVIFGKD, score 73) that correspond to the protein encoded by ORF G18_3459 (YP_004200169) in the genome of Geobacter sp. M18 (accession no. NC_014973), which was isolated from the uranium bioremediation site at Rifle, CO, USA (Lovley et al., 2011). This protein, annotated as a decaheme $C$-type cytochrome, was designated GscA.

\section{GscA in Geobacter sp. and groundwater}

The GscA of Geobacter sp. M18 (GM18_3459) consists of 1027 amino acids with 10 typical hemebinding motifs (CXXCH) (Figure 2). PSORTb (http:// www.psort.org/psortb/) predicted GscA to be extracellular (score, 9.34). SignalP 3.0 (http://www.cbs. $\mathrm{dtu} . \mathrm{dk} /$ services/SignalP/) analyses predicted a signal peptide exists in GM18_3459 with a cleavage site between amino acids 26 and 27 . Topology prediction with TMHMM2.0 (http://www.cbs.dtu.dk/services/ TMHMM-2.0/) suggested that GscA has a transmembrane helix at the N-terminal region. LipoP 1.0 (http://www.cbs.dtu.dk/services/LipoP/) suggested
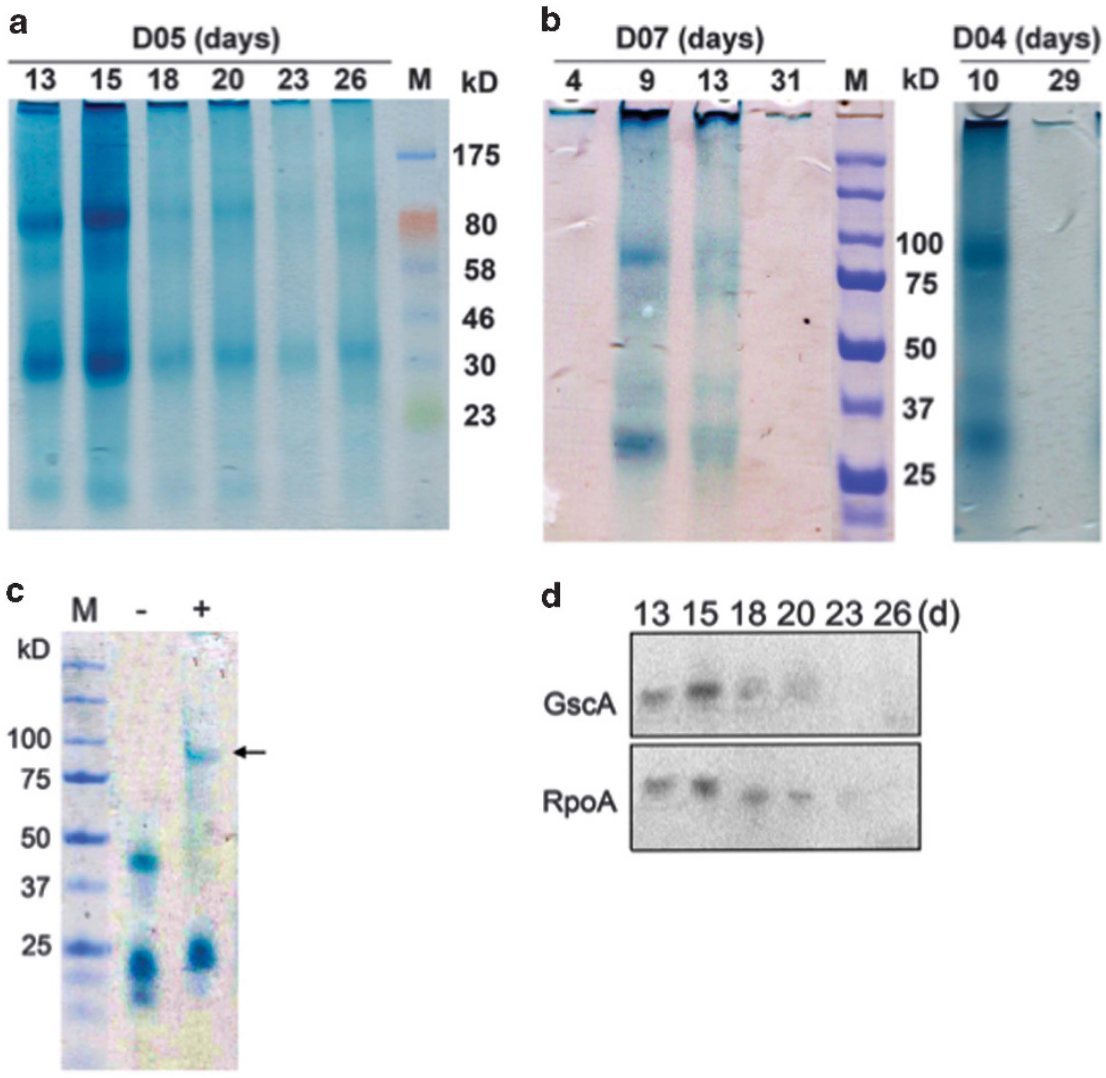

d
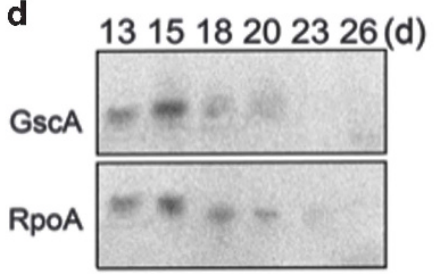

Figure 1 Detection of $c$-type heme-containing proteins during in situ uranium bioremediation. The groundwater samples were collected at the Rifle site in 2007 (a) and 2008 (b). Proteins extracted from the groundwater (6 mg) were separated by SDS-PAGE, and visualized with heme staining. Lane M, molecular weight prestained standards. Previous studies have demonstrated an abundance of Geobacter in 2007 D05 samples on days 13 and 15, but not on subsequent days (Yun et al., 2011); in 2008 D07 samples on days 9 and 13, but not day 31 (Yun et al., 2011); and for 2008 D04 samples for day 10, but not day 29 (Wilkins et al., 2011). GscA was expressed in E. coli BL21 (DE3) with the plasmid-containing genes for cytochrome maturation proteins (Arslan et al., 1998) and total proteins (10 mg) were separated by SDS-PAGE and visualized by heme staining (c). Lane - and + indicate no addition of IPTG and addition of IPTG, respectively. Abundance of GscA and Geobacter RpoA in the groundwater of the well D05 in 2007 was analyzed by western blot (d). 
that GscA has high probability (score, 26.94) to be a lipoprotein.

Amino acid sequences of GscA were compared with the GenBank databases using BlastP (Altschul et al., 1997). Within Geobacter sp., GM18_3459 homologs include: GM18_3465 of Geobacter sp. M18 (YP_004200175, 44\% identity), GM21_0875 of Geobacter sp. M21 (YP_003020700, 40\% identity) and Gbem_3371 (YP_002140162, 39\% identity) of G. bemidjiensis (Figure 2). These species are closely related to Geobacter sp. in Subsurface Clade I that are abundant in many subsurface environments (Holmes et al., 2007; Wilkins et al., 2009). G. lovleyi, which is in the phylogenetic clusters known as Subsurface Clade II (Lovley et al., 2011), also contains a GscA homolog (Glov_2292 of G. lovleyi strain SZ (YP_001952528, 45\% identity). There was no protein with significant similarity to GscA in the genomes of $G$. sulfurreducens, $G$. metallireducens, G. uraniireducens or G. daltonii. The two GscA homologs of Geobacter sp. M18 have ca. 120 more amino acids after the putative signal peptide compared with the other species (Figure 2). Other than Geobacter sp., similar proteins were found in Rhodoferax ferrireducens, Candidatus Solibacter usitatus, Anaeromyxobacter dehalogenans and Shewanella oneidensis with identities of $\sim 30 \%$.

Geobacter sp. M18 is not well-characterized and is difficult to grow because it can only be grown on $\mathrm{Fe}$ (III) oxide, on which it grows very slowly (Lovley et al., 2011). In contrast, the closely related $G$. bemidjiensis, which is also a member of the Geobacter subsurface clade 1, has been substantially characterized and is readily grown with soluble electron acceptors such as fumarate (Aklujkar et al., 2010; Lovley et al., 2011; Ueki, 2011; Yun et al., 2011). The GscA of G. bemidjiensis (Gbem_3371) was successfully expressed in E. coli. Heme staining confirmed that it was a $c$-type cytochrome (Figure 1c).

In order to further evaluate the presence of GscA in groundwater samples, an antibody to a peptide conserved in the GscA homologs in Subsurface Clade I Geobacter sp. was generated. Western blot analysis with this antibody confirmed the presence of GscA in the groundwater (Figure 1d, Supplementary Information 1), exhibiting the same expression pattern as the predominant hemestaining upper band shown in the original proteomic analysis (Figure 1a). The abundance of GscA tracked with the abundance of Geobacter sp. as indicated by the abundance of the housekeeping protein RpoA (Figure 1d, Supplementary Information 1).

Phylogenetic diversity of GscA in the in situ uranium bioremediation site

In order to evaluate the diversity of GscA homologs expressed during active growth of Geobacter sp. in the subsurface, gSCA sequences were amplified with degenerate primers from subsurface genomic DNA collected from well D07, at 15 days after the start of acetate injection in 2007. Previous analysis suggested that Geobacter sp. were abundant during this time (Williams et al., 2011) and analysis of a $16 \mathrm{~S}$ ribosomal RNA gene clone library generated with the environmental DNA from this time point revealed that Geobacter sp. accounted for ca. $85 \%$ of the sequences recovered (Figure 3a). Both heme-staining and western blot analyses demonstrated that GscA homologous proteins were abundant in this sample (Figure 3b).

A total of 108 partial amino acid sequences of GscA homologs were recovered from this groundwater sample (Figure 3c). All the amplified sequences had highest similarity to Geobacter GscA homologs. They were distributed into five subclusters (I, II, III, IV and V) with 90\% amino acid sequence consensus cutoff for each cluster. The majority (85 of 108) belonged to subcluster I, which includes GM18_3459 of Geobacter sp. M18, the protein initially identified with LC/MS/MS analyses. There were no GscA-like sequences that could be grouped with the GscA of G. lovleyi (Glov_2292) or GM18_6465, the other GscA homolog of Geobacter sp. M18. No GscA homologs of $R$. ferrireducens were detected, consistent with previous findings that Geobacter sp. outcompete Rhodoferax sp. once acetate is added to the subsurface at the Rifle site (Mouser et al., 2009; Zhuang et al., 2011). No Shewanella GscA homologs were detected, consistent with the general lack of abundance of Shewanella sp. in Fe(III)-reducing subsurface environments (Snoeyenbos-West et al., 2000).

Expression of GscA compensates for the loss of OmcS in G. sulfurreducens

The lack of a developed genetic system for any of the subsurface clade I Geobacter sp. prevented evaluation of the GscA function in the available pure cultures. As an alternative, the possibility that expression of gscA might complement the deletion of omcS in G. sulfurreducens was evaluated because: (1) GscA and OmcS are both outer-surface proteins and (2) the deletion and complementation of omcS in $G$. sulfurreducens yields a very clear phenotype for the capacity for Fe(III) oxide reduction (Mehta et al., 2005). Therefore, the gscA of G. bemidjiensis was introduced into the previously described (Mehta et al., 2005) omcS-deficient strain of G. sulfurreducens on a plasmid under the control of an IPTG-inducible promoter. As expected from the previous results (Mehta et al., 2005), the omcS-deficient strain of G. sulfurreducens did not effectively reduce Fe(III) oxide (Figure 4a). However, the strain with the IPTGinducible gscA effectively reduced $\mathrm{Fe}(\mathrm{III})$ oxide in the presence of IPTG (Figure 4b). The lag period prior to $\mathrm{Fe}(\mathrm{III})$ oxide reduction was slightly longer than the wild-type strain, but the rate of Fe(III) oxide reduction was comparable between the wildtype strain (1.4 mM $\mathrm{Fe}$ (II) produced/day) and the gscA-induced strain (1.1 mm Fe(II) produced/day) 
signal peptide

GM 18_3459 GM 18_3465 GM21_0875 Gbem_3371

GIov_2292

GM 18_3459 GM 18_3465 GM21_0875

Gbem_3371

GI ov_2292

GM18_3459 GM 183465 GM21_0875 Gbem_3371 GI ov_2292

GM 18_3459 GM18_3465 GM21_0875

Gbem_3371

Glov_2292

GM 18_3459 GM 18_3465 GM21_0875 Gbem_3371 GI ov_2292

GM 18_3459 GM 18_3465 GM21_0875

Gbem_3371

GIov_2292

GM 18_3459 GM 18_3465 GM21_0875 Gbem_3371 Glov_2292

GM18_3459 GM18_3465 GM21_0875 Gbem_3371

Glov_2292

GM18_3459 GM18_3465 GM21_0875 Gbem_3371 Glov_2292

GM18_3459 GM18_3465 GM21_0875 Gbem_3371

Glov_2292

GM18_3459 GM18_3465 GM21_0875

Gbem_3371 GI ov_2292

\begin{abstract}
MIG---ANLRYLVALVVCVLL----PLAGCSGGGSSTKLTEKGTEVTVSGKVOVAKSAAKTVFLSSTSAGAVNNVFVYOALDGAQLGTAAISSDGTFSNLSFTLPATKTILVFKAVVAQG MI G----RNLRYLVALVVCVLL-----PLAGCSGGGSTTKITEKGTEVTVGGKLDVAKAAAKTAFISSTSAGAVNHVFVYNAODGAQLGTAVIDSSGSFRDLTFTLPATKTVLVFKAIVAQG MQRKLLKRSSSFL I ALTAAATL----FLGGCEGDKGDPGAPGRD-MQGTLWKKFSTFL I ASTAAAAL---FLGGCEDKGDRGEPGKN--MLK----RN---MISTAGCLLLFAASLFTGCSGGGGGGSTPAPS
\end{abstract}

$\star \quad: \quad::: \quad * \quad: \star \star \star \star *, \cdots$

TFRTVVPIDLSNPPPAGT I TGSNPISIEI SQDSTNRTILVSQLLGLTGILGDANQTLASVSKTYTDAATLWVNNGGQQLAFSSTGLALSGKFSSAALLPAQQDANILGAEDLNNMTL---DG TYRSLVPVOLSNPPAAGAITASSPISIQI SQQSTDICTAVSALMGLTGQLGDANQTLASVSKTYTDSADAVVDAGGQILAYSTTGLALAGTLSNSNLLPATSASTLTYDDLNNTQL----SG NISSLTTTQRVDLEFDQTNS NISSLTPQQQANLTFDQTNS DAATMSNETLSAVSL---RA

SISSVAIPGSKPIVSFTVTNKDTGKGIKG LKTFNLVIAQLKPGTDGS PDEWLSYMVTGSTSRPTTOS-GYTVIONGDGSYTVIFGKDIKAG----SVTSAFIPGNNPIVNYTVTNKATGKGITG--

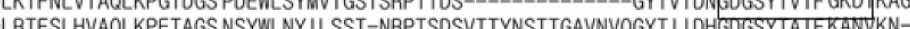

VVTGVT IA-SPPVVTFKI I DV-NGNPVRGIGQ--RSANGQLTNLAFS I AKLVPGTDGS PSTWVNYVVTSS-PT--GTTPVA--ASRP-TROREGTLVENSDGSYTYTF ARD I AQAQTLANG TVTSVS IS-SPPVVKFKILDS-NGNPVI I I GA--RNSTGQLQNLGFTLAKLVPGTNGS PSHWVNYLVTTV-PAPGSSTPAA--ARPP-ERDREGTLI ONGDGTYQYTF ARD I TQ I QTQVNA

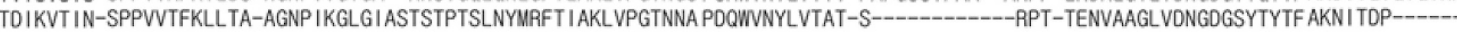

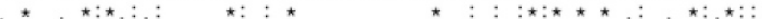$$
::: \leqslant \star \star: \star \quad \star \quad::
$$

---1GGTVTYDANL THRLMVGVRS-----

GVA--PT----LLKOMTTTEACNECHGK

I GVTTPH-GGRGDVKYCMMCHTSQRANGRTASTSVGGVFTGT-

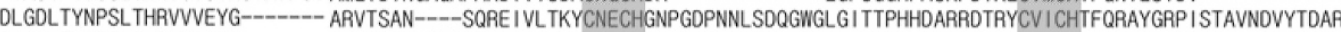
TGNNRRSDLGDLTYQPSLTHRLVIQYG------ QVVTSST-SNAQERNIVFTKYCNECHGSPGDPNNLNDLGFGLGITTPH-SGRVDTRYCAICHTSQRAYGHAISVATNGAFTDG-TQTNGVTYQPTLTHRLAIQIS------- KAVSATD----TQREI TL I AKCNECHEK--------LAFH---GGGRVETRYCVVCHTDQRKI GRTNSASTGGVFTGT-

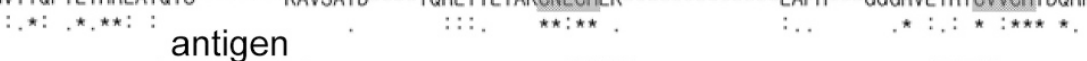

TYIA-------DGEVSGEFVTMI IKIHMGSRLTKTGYNYAGVLFNEVILP--KDVRNCROCHKGOTTAELALAAQANNWKTKPSRKACGACHDGVNFATGAGHD-GG----AQASDA AGETNGDFTPFIHKLHMGEELSPAE-TILGVDTAEITYP--_DDIRNCAUCHKG--------VDGNNWKTKPTRKACGSCHSTTDFTAHE----G-----GQTSDO TYVTAQT----GANGEVLGEFVTLVHKIHMGDRL TKSGYNYAGVMFDQLVSP--TDPALCRKCHRGOTAEQLAAAPQGONWHOMPSPKACGSCHDGVNFQTGEGHSLGN---L VQTNDS TFVTAETTTADVNTDDVQVLGEFVTMVHKI HMGNRLTETGYNYAGVTFNT I AYS---QDPALCRKCHRGOTPQQLAVTPQGNNWNTMPSRKACGSCHDNVHFSTGLNHD-GN----LPQANDT TYIA-- DGEVQGDFA I MVHKI HMGNRL TKTGYOYAGVKYND I GYSM I OGQ I NCLKCH VKSD---AAPQGONWKAKPSRAACGSCHDN I NFATGANSKAGGAVH I I QTSDA

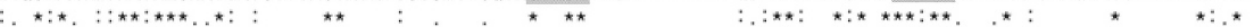

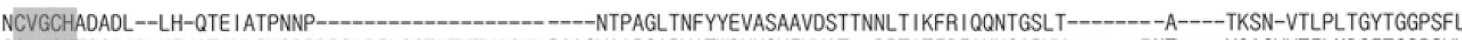
SCAACHTGGI AD-VEVATAHLPVQDPDPSAPELGGTNTHTYAGYL PAAGVAIPGAPVI TWOVKSVEVVAT--RPTITFRF I KNGAPVV------F NT----YQAGVVTELMDGFTGSPSVY ACTGCHNATGVQQNH-QSRRLTTTNT-_-_-_-_-_-_-_TPAGYVNFFYEIASATVDAATNNLSVRFRI QQSTDSAANKTNVVF TGPGAVTGTP-ADAVISGFSGSPSFL

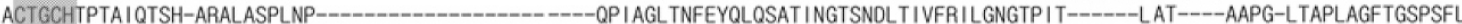

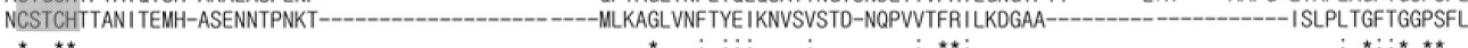
${ }^{\star} \quad:::: . .:$ 


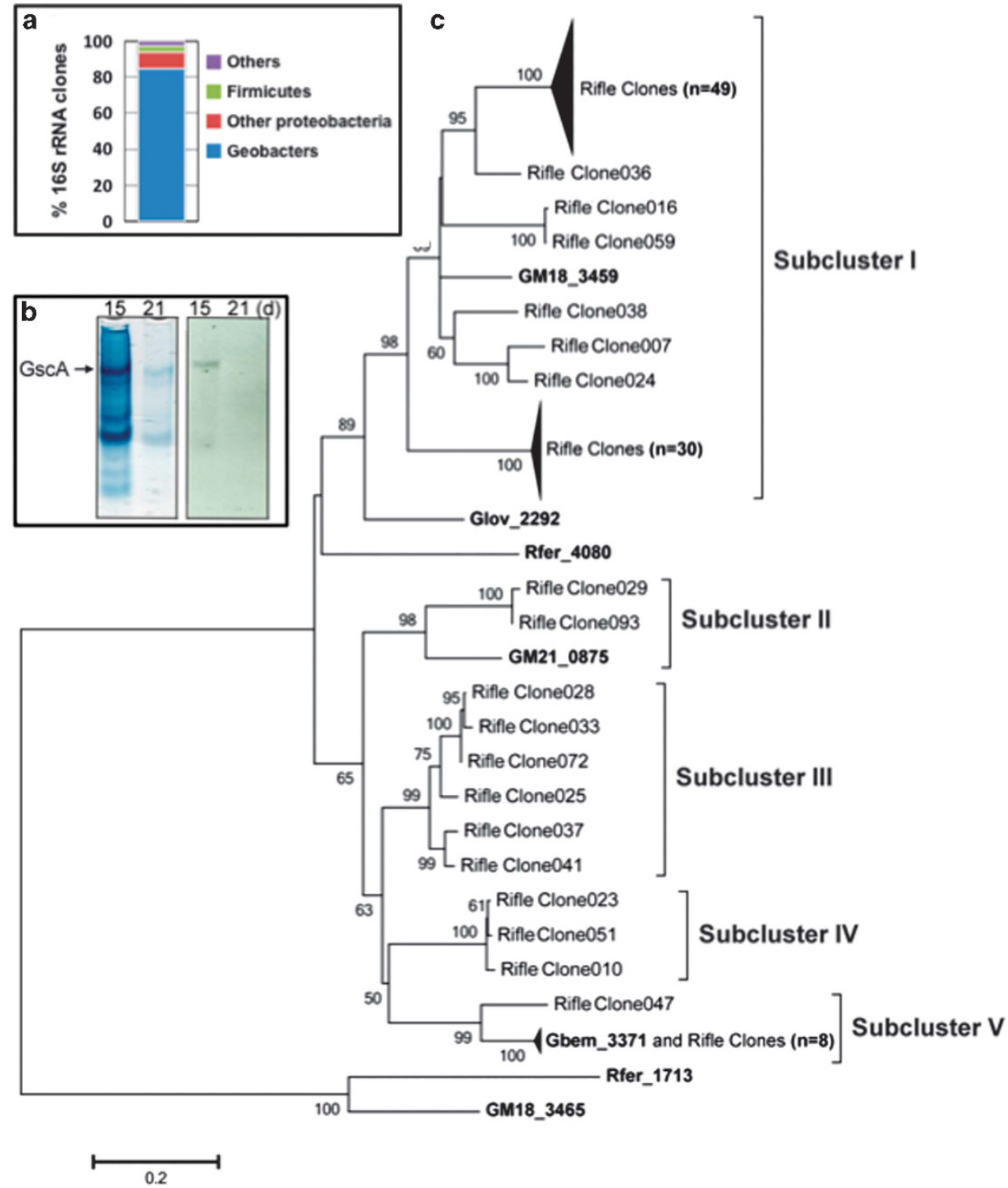

Figure 3 Phylogenetic relationship of GscA. (a) Microbial community composition based on a 16 S rRNA clone library generated with the environmental DNA collected from well D07 at day 15 in 2007. (b) Abundance of GscA analyzed by the heme-staining method and western blot. (c) Comparison of amino acid sequences of GscA recovered from groundwater of Rifle, CO, and those from Geobacter isolates and R. ferrireducens. The tree was constructed by using the Neighbor-Joining method (Saitou and Nei, 1987). The percentage of replicate trees in which the associated taxa clustered together in the bootstrap test (1000 replicates) is shown next to the branches. The scale bar represents 0.2 amino acid substitutions per site.

during the linear phase of Fe(III) reduction. The omcS-deficient strain with IPTG-inducible gscA did not reduce Fe(III) oxide in the absence of the inducer and a strain with the same plasmid, but lacking gsc $A$, did not reduce Fe(III) oxide in the presence of IPTG (Figure 4b).

After OmcS, the outer-membrane $c$-type cytochrome $\mathrm{OmcB}$ is typically the most abundant outer-surface $c$-type cytochrome when $G$. sulfurreducens is growing on Fe(III) oxide. The omcB-deficient strain is unable to reduce $\mathrm{Fe}(\mathrm{III})$ (Leang et al., 2003; Qian et al., 2007). Expression of GscA did not enable the omcB-deficient strain to reduce $\mathrm{Fe}(\mathrm{III})$, suggesting that the restoration of the capacity for Fe(III) oxide reduction when GscA was expressed in the omcS-deficient strain was specifically related to replacing the OmcS function.

In order to further evaluate how the expression of GscA could compensate for the loss of OmcS, the localization of GscA expressed in G. sulfurreducens was investigated. Attempts to visualize GscA with immunogold labeling using the antibody developed from a GscA peptide, in a manner similar to that reported for the localization of OmcS (Leang et al., 2010), were unsuccessful, presumably because the antibody did not recognize the undenatured protein. 

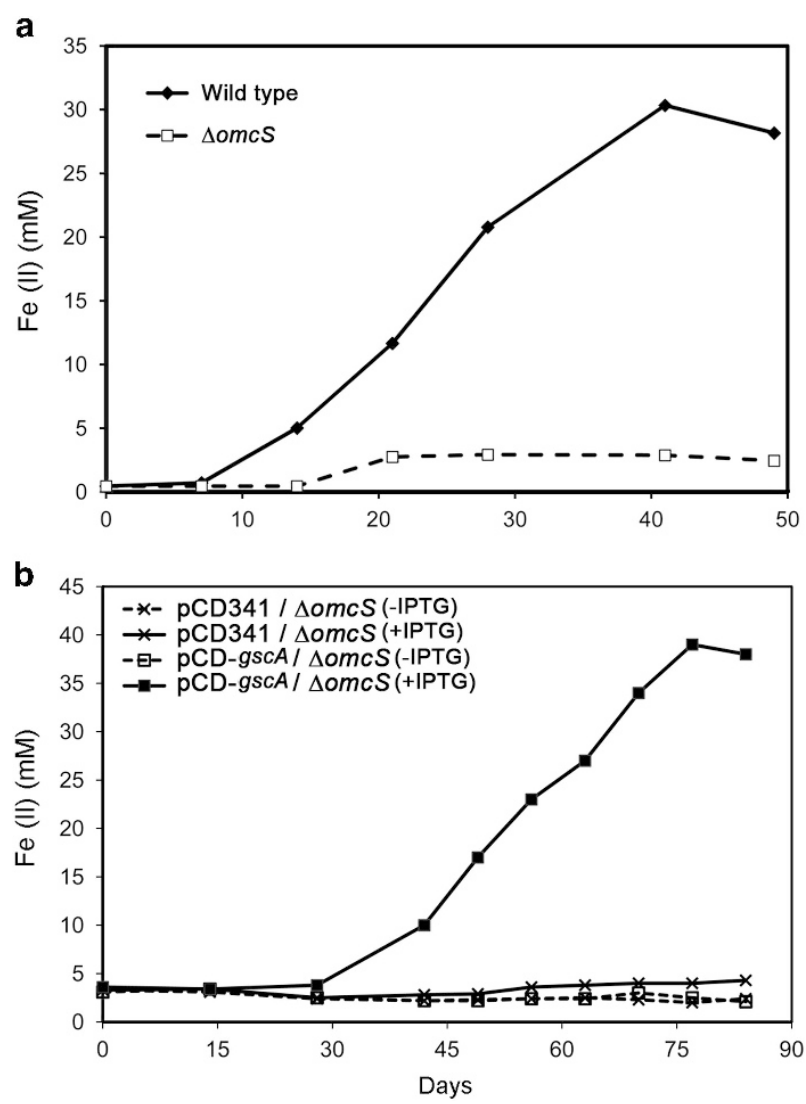

Figure 4 Fe(III) oxide reduction. Fe(III) reducing ability of $G$. sulfurreducens wild-type PCA strain (Wild type) and the G. sulfurreducens omcS-deletion mutant $(\Delta o m c S)$ (a), or the $\triangle$ omcS harboring the empty vector (pCD341) and the gscA expressing plasmid (pCD-gscA) (b) was evaluated. IPTG $\left(1 \mathrm{mg} \mathrm{ml}^{-1}\right)$ was added to induce expression of gscA. Data shown are a representative of triplicate experiments with similar results.

Atomic force microscopy is an alternative to visualizing OmcS on pili, which does not require antibodies (Malvankar et al., 2012). Atomic force microscopy revealed cytochrome-like globules on the pili of the $G$. sulfurreducens omcS-deficient strain expressing GscA (Figure 5a), similar in appearance to previously reported wild-type cells (Malvankar et al., 2012). The heights of the globules and the pili were consistent with the known sizes of cytochromes and pili, respectively (Figure 5b). In contrast, the pili of the omcS-deficient strain without gscA were bare (Figures 5c and d). These results suggest that GscA was localized along the pili and was able to substitute for $\mathrm{OmcS}$ to facilitate electron transfer between the pili and Fe(III) oxide.

\section{Implications}

These results suggest that one of the most abundant $c$-type cytochromes during in situ uranium bioremediation functions in a manner similar to the cytochrome OmcS of G. sulfurreducens. The proposed role of OmcS is to facilitate electron transfer from pili to Fe(III) oxides (Lovley, 2011, 2012). The finding that magnetite, which associates with pili, can rescue the ability of omcS-deficient G. sulfurreducens to reduce Fe(III) oxide demonstrated that there is no specific requirement for OmcS for this electron transfer function (Liu et al., 2015). If a mineral can substitute for OmcS then it may not be surprising that another $c$-type cytochrome can also fulfill this function. However, there do not appear to be any other $c$-type cytochromes among the over 100 encoded in the $G$. sulfurreducens genome (Methe et al., 2003) that can substitute for $\mathrm{OmcS}$, suggesting that GscA possess some unique properties that facilitate its association with pili. Elucidation of the salient features will require extensive further investigation with approaches such as site-directed mutagenesis of the gSCA gene sequence expressed in the omcS-deficient strain of $G$. sulfurreducens.

The poor conservation of $c$-type cytochromes across Geobacter sp. (Butler et al., 2009, 2010) suggests that in different Geobacter sp. alternative cytochromes are likely to have similar functions. Although genes aligned with $C$-type cytochrome genes on Geobacter chromosomes are often highly conserved, the $c$-type cytochrome sequences can vary significantly, suggesting that there is often little selective pressure for specific $c$-type cytochrome structure as long as the capacity for electron transfer inherent in $c$-type cytochromes is retained (Butler et al., 2009, 2010).

The apparent role of GscA in Fe(III) oxide reduction and its abundance during in situ uranium bioremediation is consistent with the concept that Geobacter sp. primarily grow via $\mathrm{Fe}(\mathrm{III})$ oxide reduction in uranium-contaminated aquifers (Finneran et al., 2002). Although growth via U(VI) reduction is feasible (Lovley et al., 1991; Sanford et al., 2007), even in uranium-contaminated aquifers the availability of $U$ (VI) ( $\mu \mathrm{M}$ concentrations) is typically much less than Fe (III) oxide. In contrast to the specific need for OmcS for Fe(III) oxide reduction in G. sulfurreducens, many outer-surface $c$-type cytochromes appear to have the ability to reduce U(VI) (Shelobolina et al., 2007; Orellana et al., 2013). A similar non-specific reduction of U(VI) by outer-surface cytochromes seems probable for the Geobacter sp. that are enriched during in situ uranium bioremediation.

In contrast to $G$. sulfurreducens and $G$. metallireducens, which are amenable to genetic manipulation (Coppi et al., 2001; Tremblay et al., 2012), many of the available isolates from the Subsurface Clade I of Geobacter sp. (Holmes et al., 2007) are difficult to cultivate on solidified medium, complicating the development of genetic tools. Genes for central metabolism are typically highly conserved among Geobacter sp. and thus functional studies from G. sulfurreducens have successfully been used to identify target genes or proteins that have been useful in diagnosing the physiological status of Geobacter sp. in subsurface environment approaches (Lovley et al., 2011; Mahadevan et al., 2011). The approach described here of evaluating the function of genes found in Subsurface Clade I Geobacter sp. 

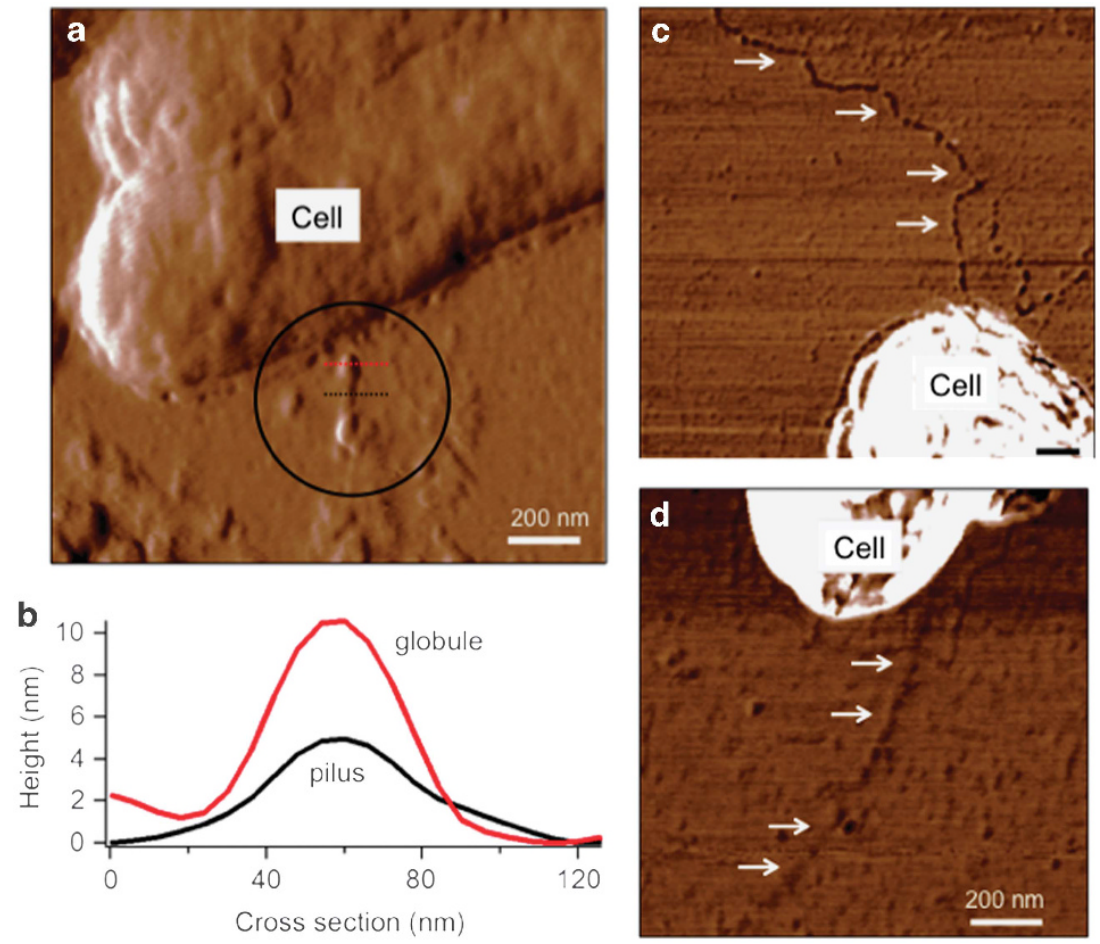

Figure 5 AFM. (a) G. sulfurreducens $\Delta o_{c} S /$ pCD-gscA. Pilus and associated cytochrome-like globules are shown in a circle. (b) Corresponding height profiles at the section indicated in a. Black line corresponds to pilus filament whereas red line corresponds to a cytochrome-like globule aligned along the pilus filament. (c and d) AFM images of bare pili with no associated globules in G. sulfurreducens $\Delta o m c S / p C D 341$. All scale bars $=200 \mathrm{~nm}$. Pili are indicated by arrows. The data are a representative of three biological replicates.

by determining the capacity for those genes to restore functions in $G$. sulfurreducens is expected to accelerate the understanding of the physiology and ecology of subsurface Geobacter sp.

\section{Conflict of Interest}

The authors declare no conflict of interest.

\section{Acknowledgements}

This research was supported by the Office of Science (BER), US Department of Energy Genomics Science Program (Cooperative Agreement No, DE-FC02-ER63446) and Subsurface Biogeochemical Research Program (Grant No. DE-SC0006790). We thank Paula Mouser, Lucie N'Guessan, Hila Elifantz, Dawn Holmes, Melissa Barlett, Marzia Miletto and Kenneth Williams for collecting and sharing groundwater samples from Rifle in 2007 and 2008. We are grateful to Joy Ward and Manju Sharma for technical support.

\section{References}

Aklujkar M, Young ND, Holmes D, Chavan M, Risso C, Kiss HE et al. (2010). The genome of Geobacter bemidjiensis, exemplar for the subsurface clade of Geobacter species that predominate in Fe(III)-reducing subsurface environments. BMC Genomics 11: 490.
Altschul S, Madden T, Schaffer A, Zhang J, Zhang Z, Miller W et al. (1997). Gapped BLAST and PSI-BLAST: a new generation of protein database search programs. Nucleic Acids Res 25: 3389-3402.

Anderson RT, Vrionis HA, Ortiz-Bernad I, Resch CT, Long PE, Dayvault R et al. (2003). Stimulating the in situ activity of Geobacter species to remove uranium from the groundwater of a uranium-contaminated aquifer. Appl Environ Microbiol 69: 5884-5891.

Arslan E, Schulz H, Zufferey R, Kunzler P, Thony-Meyer L. (1998). Overproduction of the Bradyrhizobium japonicum c-type cytochrome subunits of the cbb3 oxidase in Escherichia coli. Biochem Biophys Res Commun 251: 744-747.

Bollag DM, Rozycki MD, Edelstein SJ. (1996). Protein Methods. 2nd edn NY, USA: Willey-Liss Inc.

Butler JE, Young ND, Lovley DR. (2009). Evolution from a respiratory ancestor to fill syntrophic and fermentative niches: comparative fenomics of six Geobacteraceae species. BMC Genomics 10: 103.

Butler JE, Young ND, Lovley DR. (2010). Evolution of electron transfer out of the cell: comparative genomics of six Geobacter genomes. BMC Genomics 11: 40.

Caccavo F, Lonergan DJ, Lovley DR, Davis M, Stolz JF, McInerney MJ. (1994). Geobacter sulfurreducens sp. nov., a hydrogen- and acetate-oxidizing dissimilatory metal-reducing microorganism. Appl Environ Microbiol 60: 3752-3759.

Callister SJ, Wilkins MJ, Nicora CD, Williams KH, Banfield JF, VerBerkmoes NC et al. (2010). Analysis of biostimulated microbial communities from two field experiments reveals temporal and spatial differences in proteome profiles. Environ Sci Technol 44: 8897-8903. 
Chin KJ, Esteve-Nunez A, Leang C, Lovley DR. (2004). Direct correlation between rates of anaerobic respiration and levels of mRNA for key respiratory genes in Geobacter sulfurreducens. Appl Environ Microbiol 70: 5183-5189.

Coppi MV, Leang C, Sandler SJ, Lovley DR. (2001). Development of a genetic system for Geobacter sulfurreducens. Appl Environ Microbiol 67: 3180-3187.

DeSantis TZ, Hugenholtz P, Keller K, Brodie EL, Larsen N, Piceno YM et al. (2006a). NAST: a multiple sequence alignment server for comparative analysis of $16 \mathrm{~S}$ rRNA genes. Nucleic Acids Res 34: W394-W399.

DeSantis TZ, Hugenholtz P, Larsen N, Rojas M, Brodie EL, Keller K et al. (2006b). Greengenes, a chimera-checked $16 \mathrm{~S}$ rRNA gene database and workbench compatible with ARB. Appl Environ Microbiol 72: 5069-5072.

Eden PA, Schmidt TM, Blakemore RP, Pace NR. (1991). Phylogenetic analysis of Aquaspirillum magnetotacticum using polymerase chain. Int J Syst Bacteriol 41: 324-325

Finneran KT, Anderson RT, Nevin KP, Lovley DR. (2002). Potential for Bioremediation of uranium-contaminated aquifers with microbial U(VI) reduction. Soil Sediment Contam 11: 339-357.

Francis Jr RT, Becker RR. (1984). Specific indication of hemoproteins in polyacrylamide gels using a doublestaining process. Anal Biochem 136: 509-514.

Holmes DE, O'Neil RA, Vrionis HA, N'Guessan LA, OrtizBernad I, Larrahondo MJ et al. (2007). Subsurface clade of Geobacteraceae that predominates in a diversity of Fe(III)-reducing subsurface environments. ISME $J \mathbf{1}$ : 663-677.

Lane DJ, Pace B, Olsen GJ, Stahl DA, Sogin ML, Pace NR. (1985). Rapid determination of $16 \mathrm{~S}$ ribosomal RNA sequences for phylogenetic analyses. Proc Natl Acad Sci USA 82: 6955-6959.

Leang C, Coppi MV, Lovley DR. (2003). OmcB, a c-type polyheme cytochrome, involved in Fe(III) reduction in Geobacter sulfurreducens. J Bacteriol 185: 2096-2103.

Leang C, Qian X, Mester T, Lovley DR. (2010). Alignment of the c-type cytochrome OmcS along pili of Geobacter sulfurreducens. Appl Environ Microbiol 76: 4080-4084.

Liu F, Rotaru AE, Shrestha PM, Malvankar NS, Nevin KP, Lovley DR. (2015). Magnetite compensates for the lack of a pilin-associated c-type cytochrome in extracellular electron exchange. Environ Microbiol 17: 648-655.

Liu X, Tremblay PL, Malvankar NS, Nevin KP, Lovley DR, Vargas M. (2014). A Geobacter sulfurreducens strain expressing pseudomonas aeruginosa type IV pili localizes OmcS on pili but is deficient in Fe(III) oxide reduction and current production. Appl Environ Microbiol 80: 1219-1224.

Lovley DR. (1991). Dissimilatory Fe(III) and Mn(IV) reduction. Microbiol Rev 55: 259-287.

Lovley DR. (2011). Live wires: direct extracellular electron exchange for bioenergy and the bioremediation of energy-related contamination. Energ Environ Sci 4: 4896-4906.

Lovley DR. (2012). Long-range electron transport to Fe(III) oxide via pili with metallic-like conductivity. Biochem Soc Trans 40: 1186-1190.

Lovley DR, Phillips EJ. (1986). Availability of ferric iron for microbial reduction in bottom sediments of the freshwater tidal potomac river. Appl Environ Microbiol 52: 751-757.
Lovley DR, Phillips EJ. (1987). Rapid assay for microbially reducible ferric iron in aquatic sediments. Appl Environ Microbiol 53: 1536-1540.

Lovley DR, Phillips EJP, Gorby YA, Landa ER. (1991). Microbial reduction of uranium. Nature 350: 413-416.

Lovley DR, Stolz JF, Nord GL, Phillips EJP. (1987). Anaerobic production of magnetite by a dissimilatory iron-reducing microorganism. Nature 330: 252-254.

Lovley DR, Ueki T, Zhang T, Malvankar NS, Shrestha PM, Flanagan KA et al. (2011). Geobacter: the microbe electric's physiology, ecology, and practical applications. Adv Microb Physiol 59: 1-100.

Mahadevan R, Palsson BO, Lovley DR. (2011). In situ to in silico and back: elucidating the physiology and ecology of Geobacter spp. using genome-scale modelling. Nat Rev Microbiol 9: 39-50.

Malvankar NS, Lovley DR. (2014). Microbial nanowires for bioenergy applications. Curr Opin Biotechnol 27: 88-95.

Malvankar NS, Tuominen MT, Lovley DR. (2012). Lack of cytochrome involvement in long-range electron transport through conductive biofilms and nanowires of Geobacter sulfurreducens. Energ Environ Sci 5: 8651-8659.

Malvankar NS, Vargas M, Nevin KP, Franks AE, Leang C, Kim BC et al. (2011). Tunable metallic-like conductivity in microbial nanowire networks. Nat Nanotechnol 6: $573-579$.

Malvankar NS, Yalcin SE, Tuominen MT, Lovley DR. (2014). Visualization of charge propagation along individual pili proteins using ambient electrostatic force microscopy. Nat Nanotechnol 9: 1012-1017.

Mehta T, Coppi M, Childers S, Lovley D. (2005). Outer membrane c-type cytochromes required for Fe(III) and Mn(IV) oxide reduction in Geobacter sulfurreducens. Appl Environ Microbiol 71: 8634-8641.

Merkley ED, Anderson BJ, Park J, Belchik SM, Shi L, Monroe ME et al. (2012). Detection and identification of heme c-modified peptides by histidine affinity chromatography, high-performance liquid chromatography-mass spectrometry, and database searching. J Proteome Res 11: 6147-6158.

Methe BA, Nelson KE, Eisen JA, Paulsen IT, Nelson W, Heidelberg JF et al. (2003). Genome of Geobacter sulfurreducens: metal reduction in subsurface environments. Science 302: 1967-1969.

Mouser PJ, N' Guessan AL, Elifantz H, Holmes DE, Williams KH, Wilkins MJ et al. (2009). Influence of heterogeneous ammonium availability on bacterial community structure. Environ Sci Technol 43: 4386-4392.

Nevin KP, Holmes DE, Woodard TL, Hinlein ES, Ostendorf DW, Lovley DR. (2005). Geobacter bemidjiensis sp. nov. and Geobacter psychrophilus sp. nov., two novel Fe(III)-reducing subsurface isolates. Int J Syst Evol Microbiol 55: 1667-1674.

Orellana R, Leavitt JJ, Comolli LR, Csencsits R, Janot N, Flanagan KA et al. (2013). U(VI) reduction by diverse outer surface c-type cytochromes of Geobacter sulfurreducens. Appl Environ Microbiol 79: 6369-6374.

Pazour GJ, Agrin N, Leszyk J, Witman GB. (2005). Proteomic analysis of a eukaryotic cilium. J Cell Biol 170: 103-113.

Qian X, Mester T, Morgado L, Arakawa T, Sharma ML, Inoue $\mathrm{K}$ et al. (2011). Biochemical characterization of purified OmcS, a c-type cytochrome required for insoluble Fe(III) reduction in Geobacter sulfurreducens. Biochim Biophys Acta 1807: 404-412. 
Qian X, Reguera G, Mester T, Lovley DR. (2007). Evidence that $\mathrm{OmcB}$ and $\mathrm{OmpB}$ of Geobacter sulfurreducens are outer membrane surface proteins. FEMS Microbiol Lett 277: 21-27.

Reguera G, McCarthy KD, Mehta T, Nicoll JS, Tuominen MT, Lovley DR. (2005). Extracellular electron transfer via microbial nanowires. Nature 435: 1098-1101.

Romine MF, Elias DA, Monroe ME, Auberry K, Fang R, Fredrickson JK et al. (2004). Validation of Shewanella oneidensis MR-1 small proteins by AMT tag-based proteome analysis. OMICS 8: 239-254.

Saitou N, Nei M. (1987). The neighbor-joining method: a new method for reconstructing phylogenetic trees. Mol Biol Evol 4: 406-425.

Sanford RA, Wu Q, Sung Y, Thomas SH, Amos BK, Prince EK et al. (2007). Hexavalent uranium supports growth of Anaeromyxobacter dehalogenans and Geobacter spp. with lower than predicted biomass yields. Environ Microbiol 9: 2885-2893.

Shelobolina ES, Coppi MV, Korenevsky AA, DiDonato R, Sullivan SA, Konishi $\mathrm{H}$ et al. (2007). Importance of c-type cytochromes for U (VI) reduction by Geobacter sulfurreducens. BMC Microbiol 7: 16.

Snoeyenbos-West OL, Nevin KP, Anderson RT, Lovley DR. (2000). Enrichment of Geobacter species in response to stimulation of $\mathrm{Fe}(\mathrm{III})$ reduction in sandy aquifer sediments. Microb Ecol 39: 153-167.

Studier FW, Rosenberg AH, Dunn JJ, Dubendorff JW. (1990). Use of T7 RNA polymerase to direct expression of cloned genes. Methods Enzymol 185: 60-89.

Tamura K, Dudley J, Nei M, Kumar S. (2007). MEGA4: molecular evolutionary genetics analysis (MEGA) software version 4.0. Mol Bio Evol 24: 1596-1599.

Thomas PE, Ryan D, Levin W. (1976). An improved staining procedure for the detection of the peroxidase activity of cytochrome P-450 on sodium dodecyl sulfate polyacrylamide gels. Anal Biochem 75: 168-176.

Thompson JD, Higgins DG, Gibson TJ. (1994). CLUSTAL W: improving the sensitivity of progressive multiple sequence alignment through sequence weighting, position-specific gap penalties and weight matrix choice. Nucleic Acids Res 22: 4673-4680.

Tremblay P-L, Aklujkar M, Leang C, Nevin KP, Lovley D. (2012). A genetic system for Geobacter metallireducens: role of the flagellin and pilin in the reduction of Fe(III) oxide. Environ Microbiol Rep 4: 82-88.
Ueki T. (2011). Identification of a transcriptional repressor involved in benzoate metabolism in Geobacter bemidjiensis. Appl Environ Microbiol 77: 7058-7062.

Vargas M, Malvankar NS, Tremblay PL, Leang C, Smith JA, Patel $\mathrm{P}$ et al. (2013). Aromatic amino acids required for pili conductivity and long-range extracellular electron transport in Geobacter sulfurreducens. mBio 4: e00105-e00113.

Wilkins MJ, Callister SJ, Miletto M, Williams KH, Nicora CD, Lovley DR et al. (2011). Development of a biomarker for Geobacter activity and strain composition; Proteogenomic analysis of the citrate synthase protein during bioremediation of U(VI). Microb Biotechnol 4: 55-63.

Wilkins MJ, VerBerkmoes NC, Williams KH, Callister SJ, Mouser PJ, Elifantz $\mathrm{H}$ et al. (2009). Proteogenomic monitoring of Geobacter physiology during stimulated uranium bioremediation. Appl Environ Microbiol 75: 6591-6599.

Wilkins MJ, Wrighton KC, Nicora CD, Williams KH, McCue LA, Handley KM et al. (2013). Fluctuations in specieslevel protein expression occur during element and nutrient cycling in the subsurface. PLoS One 8: e57819.

Williams KH, Bargar JR, Lloyd JR, Lovley DR. (2013). Bioremediation of uranium-contaminated groundwater: a systems approach to subsurface biogeochemistry. Curr Opin Biotechnol 24: 489-497.

Williams KH, Long PE, Davis JA, Wilkins MJ, N' Guessan AL, Yang L et al. (2011). Acetate availability and its influence on sustainable bioremediation of uranium-contaminated groundwater. Geomicrobiol J 28: 519-539.

Yang F, Bogdanov B, Strittmatter EF, Vilkov AN, Gritsenko M, Shi L et al. (2005). Characterization of purified c-type heme-containing peptides and identification of c-type heme-attachment sites in Shewanella oneidenis cytochromes using mass spectrometry. J Proteome Res 4: 846-854.

Yun J, Ueki T, Miletto M, Lovley DR. (2011). Monitoring the metabolic status of Geobacter species in contaminated groundwater by quantifying key metabolicproteins with Geobacter-specific antibodies. Appl Environ Microbiol 77: 4597-4602.

Zhuang K, Izallalen M, Mouser P, Richter H, Risso C, Mahadevan R et al. (2011). Genome-scale dynamic modeling of the competition between Rhodoferax and Geobacter in anoxic subsurface environments. ISME J 5: 305-316.

Supplementary Information accompanies this paper on The ISME Journal website (http://www.nature.com/ismej) 